$\Rightarrow$ NEUROIMMUNOLOGY

\section{Could antibodies cause psychosis?}

Antibodies against neuronal cell surface receptors are more common among patients with psychosis, according to new research, suggesting that psychosis could be antibodymediated. The finding raises the possibility of treating some cases of psychosis with immunotherapy.

Psychosis is a common presenting symptom of autoantibodymediated encephalitis, which most commonly involves antibodies against the $N$-methyl-D-aspartate (NMDA) receptor. This observation has generated interest in whether the autoantibodies are responsible for the psychosis, and whether psychosis that is not associated with encephalitis could be mediated by the same antibodies.

Previously, a small pilot study by Belinda Lennox - who led the new study — and her colleagues identified patients with psychosis whose serum was positive for anti-NMDA receptor antibodies. Some studies have since supported the finding, but others have been contradictory. "Our new work aimed to replicate our previous findings in a larger sample of patients from across England, and to look at a range of newly described antibodies that are seen in encephalitis, including antibodies against NMDA receptors, the $\mathrm{GABA}_{\mathrm{A}}$ receptor, LGI1 and CASPR2," explains Lennox.

The study involved 228 patients who were experiencing their first episode of psychosis and had been on antipsychotic treatment for $<6$ weeks. These patients were compared with 105 healthy controls. Blood samples from participants were analysed for antibodies against the neuronal surface antigens.

Twenty of the 228 patients were positive for at least one antibody of interest, in contrast to just four controls, although this difference was not significant. However, seven patients and no controls were positive for anti-NMDA receptor antibodies, a difference that was significant. "This rate of $3 \%$ is higher than in other studies that have looked for these antibodies in psychosis," says Lennox.

The team also analysed the clinical phenotypes of the patients with psychosis, and found no difference between antibody-positive and antibody-negative individuals. The only way to identify patients with psychosis and antibodies, they conclude, is to screen all patients who present with a first episode of psychosis.

"We are now starting a phase II randomized placebo-controlled trial of intravenous immunoglobulin and rituximab in patients with psychosis and antibodies, which will be a critical step in establishing whether these antibodies are causing psychosis," explains Lennox. "We think patients should be tested at first episode of illness, and people with psychosis and antibodies should be treated in the trial to establish whether psychiatric practice needs to change."

\section{Ian Fyfe}

ORIGINAL ARTICLE Lennox, B. R. et al. Prevalence and clinical characteristics of serum neuronal cell surface antibodies in first-episode psychosis: a case-control study. Lancet Psychiatry http://dx.doi. org/10.1016/S2215-0366(16)30375-3 (2016) 